\title{
Severity index for rheumatoid arthritis and its association with health care costs and biologic therapy use in Turkey
}

\author{
Onur Baser ${ }^{1,2^{*}}$, Erdem Baser ${ }^{3}$, Akif Altinbas $^{4}$ and Abdulkadir Burkan ${ }^{5}$
}

\begin{abstract}
Objective: This study aimed to apply the previously validated severity index for rheumatoid arthritis (SIFRA) to prevalent rheumatoid arthritis (RA) groups in Turkey and determine the effect of RA severity on health care costs and biologic use.
\end{abstract}

Methods: This retrospective study used the Turkish national health insurance database MEDULA (June 1, 2009December 31, 2011). Prevalent RA patients were required to be age 18 to 99, have two RA diagnoses at least 60 days apart and be continuously enrolled 1 year prior to (baseline period) and post (follow-up period) index date, which was the first RA claim during the identification period (June 1, 2010-December 31, 2010). SIFRA was calculated for the baseline period. Total health care costs and biologic use were examined for the follow-up period. The chi-square test was used to determine the association between SIFRA score terciles and outcomes. Generalized linear models were applied to determine health care costs while multivariate logistic regression determined the effect of SIFRA on outcome measures for biologic use.

Results: A total of 1,920 patients were identified. The mean SIFRA score was 14.21, and 7.05 (49.57\%) of the mean composed of clinical and functional status variables, followed by 6.32 (44.47\%) for medications, 0.48 (3.40\%) for radiology and laboratory findings, and 0.32 (2.25\%) for extra-articular manifestation. There was a significant variation in scores across cities. After controlling for age, gender, region, and comorbidity index, patients in the high SIFRA tercile were 5.16 times more likely to be prescribed biologics ( $p<0.001$, confidence interval [Cl]: 3.46-7.69), and incurred annual health care costs that were $€ 2,091$ higher $(p<0.001, \mathrm{Cl}: € 1,557-€ 2,625)$ than those in the low SIFRA score tercile.

Conclusion: RA severity varies throughout Turkey and is a significant determinant of health care costs and biologic therapy use. Therefore, future comparative effectiveness studies should include the severity measure in their analysis.

Keywords: Rheumatoid arthritis, Severity index, Medical costs, Real-world data analysis, Outcomes research

\section{Background}

Rheumatoid arthritis (RA), a progressive and disabling autoimmune disease, has significant economic implications for individual patients as well as a society as a whole $[1,2]$.

The worldwide prevalence of RA has been estimated at $1 \%$, but tends to be higher in elderly populations [3]. RA prevalence in the United States has been estimated

\footnotetext{
* Correspondence: onur@med.umich.edu

${ }^{1}$ Internal Medicine Department, Rheumatology Division, The University of Michigan, $211 \mathrm{~N}$ 4th Avenue, Suite 2B, Ann Arbor, MI 48104, USA

${ }^{2}$ STATinMED Research, 211 North 4th Avenue, Suite 2B, Ann Arbor, Ml 48104, USA

Full list of author information is available at the end of the article
}

at $2 \%$ for persons over the age of $60[4,5]$. There are approximately 3 million RA patients in Europe [6].

There is no curative treatment for RA and joint damage is progressive. Treatment of the diseased joints aims to slow the progression of joint damage and restore pain-free function. Prior to the advent of biologic therapies, commonly used pharmacological treatments included nonsteroidal anti-inflammatory drugs (NSAIDs), and disease modifying anti-rheumatic drugs (DMARDs), such as methotrexate, injectable gold salts, sulfasalazine and leflunomide [7]. The introduction of biologic treatment has transformed the expectations of RA management. These medications have proven effective in slowing 
disease progression, achieving sustained remission, and minimizing disease activity [8]. Although effective, biologics are an extremely expensive form of therapy [9]. The use of biologic agents among newly diagnosed RA patients has increased markedly over time, rising from 3\% in 1999 to $26 \%$ in 2006 [10]. Therefore, in the last decade, health care costs and utilization of patients with RA have been increasingly recognized.

Costs associated with RA have been estimated at $\$ 8.7$ billion annually in the United States [11]. RA is responsible for 250,000 hospitalizations and more than 9 million physician visits per year $[12,13]$. Since RA patients have a peak onset near age 40 and often live for more than 30 years with joint issues that adversely affect their function, there are significant indirect costs associated with RA [14]. In Europe, 32\% of the average annual RA costs were associated with indirect costs [2]. In a recent study, $71 \%$ of the overall RA-related costs in Turkey were associated with indirect costs [15].

An increasing proportion of the aging population [16], combined with effective but expensive RA treatment options, is resulting in the need for disease-specific techniques to estimate costs. Although many observational studies have attempted to estimate the burden of RA, a key limitation is the lack of disease severity measures in datasets [17-20].

This study used a previously validated claims-based severity index for rheumatoid arthritis to estimate the distribution of disease severity across regions in Turkey [21-23]. As a secondary objective, the association between disease severity and health care costs and utilization was analyzed among patients diagnosed with RA in Turkey. Finally, the study also examined the relationship between disease severity and biologics use.

\section{Methods}

A retrospective analysis was performed using medical and pharmacy claims and eligibility data from the research identified MEDULA dataset for diagnosed RA patients in Turkey. The MEDULA dataset encompasses 17,800 pharmacies, 5,600 general practitioners, 4,500 medical centers, 1,200 government hospitals and 338 private hospitals covering more than $80 \%$ of the Turkish population.

All patients diagnosed with RA were identified using the appropriate diagnosis codes from the International Classification of Disease Tenth Revision Clinical Modification (ICD-10-CM) for the identification period (June 1, 2010 - December 31, 2010; Figure 1). Patients were required to have two RA diagnoses at least 60 days apart. The requirement of two visits and a period between claims has been shown to increase the reliability of the RA diagnosis [14]. The date of the first diagnosis claim was designated as the index date. All patients were required to be at least age 18 years on the index date and continuously enrolled in the health plan throughout the 1-year pre- (baseline) and 1-year post-index (follow-up) periods. Since this study particularly focused on prevalent patients, an RA diagnosis during the baseline period was required. All medical claims were compiled over the study period for all remaining patients.

The severity index for rheumatoid arthritis (SIFRA) score was derived for each patient. SIFRA is composed of a set of 28 RA-related indicators from a study by Cabral $e t$ $a l$. [22]. These indicators were sub-grouped as clinical and functional status, extra-articular manifestations, surgical history and medications (Table 1). The strength of each relationship was measured from $0=$ no relationship, to $6=$ perfect relationship and assessed by six board-certified, clinically active rheumatologists according to the Delphi panel method. The index was validated and applied to the U.S. Department of Veteran Affairs, Veterans Health Administration (VHA) data [21,23].

Demographic variables such as patient gender and age were available in the data. Since Turkey is divided into seven regions, flags were created according to patient region of residence. For each city, the proportion of patients with the highest SIFRA tercile score was calculated. These

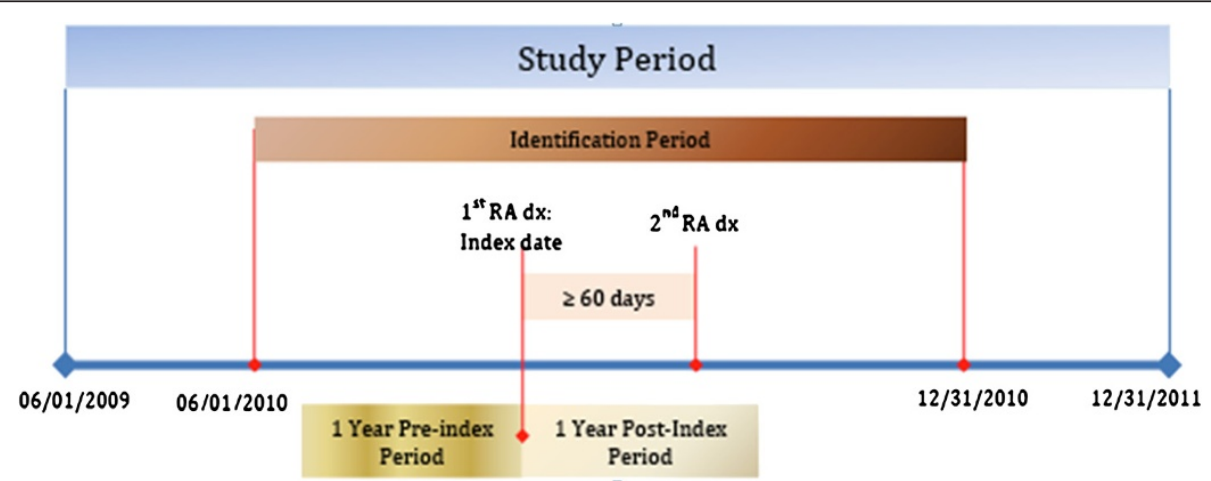

Figure 1 Study period. 
Table 1 SIFRA indicators

\begin{tabular}{|c|c|}
\hline & Rating 1 \\
\hline Radiology and Laboratory Findings & Mean (Range) \\
\hline Presence of RF Ever & $2.7(2-4)$ \\
\hline Presence of HLA Subtype & $3.0(1-4)$ \\
\hline C1-2 Subluxation & $5.2(5-6)$ \\
\hline Presence of CCP Ever & $3.0(2-4)$ \\
\hline \multicolumn{2}{|c|}{ Clinical and Functional Status Measures } \\
\hline Number of Rheumatologist Visits & $3.2(2-4)$ \\
\hline \multicolumn{2}{|l|}{ Extra-articular Manifestations } \\
\hline Pulmonary Nodules & $3.5(3-5)$ \\
\hline Subcutaneous Nodules & $2.8(2-4)$ \\
\hline Vasculitis Ever & $5.0(4-6)$ \\
\hline Felty's Syndrome Ever & $5.0(4-6)$ \\
\hline \multicolumn{2}{|l|}{ Surgical History } \\
\hline Cervical Spine Fusion & $5.5(5-6)$ \\
\hline Foot Joint Replacement & $4.2(2-6)$ \\
\hline Total Hip Replacement & $5.2(4-6)$ \\
\hline Total Knee Replacement & $5.2(4-6)$ \\
\hline Elbow Replacement & $5.3(4-6)$ \\
\hline Shoulder Replacement & $5.5(5-6)$ \\
\hline \multicolumn{2}{|l|}{ Medications } \\
\hline Any Oral Glucocorticoid Use & $2.8(2-4)$ \\
\hline Intra-articular Glucocorticoids & $2.7(2-4)$ \\
\hline \multicolumn{2}{|c|}{ Disease-modifying Anti-rheumatic Drugs } \\
\hline Azathioprine & $4.2(3-5)$ \\
\hline Cyclosporin & $4.5(4-5)$ \\
\hline Hydroxychloroquine & $2.0(2)$ \\
\hline Leflunomide & $3.8(3-4)$ \\
\hline Methotrexate & $3.8(3-4)$ \\
\hline Sulfasalazine & $2.3(2-3)$ \\
\hline \multicolumn{2}{|l|}{ Biologic Therapies } \\
\hline Adalimumab & $4.2(4-5)$ \\
\hline Infliximab & $4.0(3-5)$ \\
\hline Etanercept & $4.2(4-5)$ \\
\hline TNF (ADA, ETN, IFX) & 4.1 \\
\hline Non-TNF (ABA, RTX) & 4.8 \\
\hline
\end{tabular}

$R F=$ rheumatoid factor; $H L A=$ human leukocyte antigen; $C 1-2=$ cervical spine 1-2; $C C P=$ anti-cyclic citrullinated peptide; $T N F=$ tumor necrosis factor; $A D A=$ adalimumab; $E T N=$ etanercept; IFX=infliximab; $A B A=$ abatacept; $R T X=$ rituximab.

Note: For new biologic therapies approved since the "Delphi panel", average scores were applied depending on class. For adalimumab, infliximab, etanercept, average of TNF blockers, a rating of 4.1 was applied; for abatacept and rituximab, average of non-TNF (4.8) was applied. Also medium and small joint fusion (4.825) and large joint fusion (5.3) was applied. proportions were ranked and presented using a Turkish map to show RA severity distribution at the city level (Figure 2).

In addition to SIFRA scores, comorbidity scores using the Elixhauser index method [24] were also calculated. The Elixhauser index is defined as the sum of a comprehensive set of 30 present comorbid conditions and has been widely used to determine patient health status.

Three sets of outcomes were defined: a) total health care costs; b) total health care utilization; and c) total medication use. Total health care costs were calculated for the follow-up period as a sum of inpatient, outpatient, pharmacy and copay amounts and adjusted to 2011 costs. Hospitalization, outpatient visits, rehabilitation visits and surgery rates were also estimated for the follow-up period. In terms of medication use, rates of biologics use were calculated for the follow-up period.

The association between SIFRA terciles and outcomes were assessed using the Chi-square test.

In order to estimate the effect of the severity score on health care costs, generalized linear models (GLMs) were used [25]. Following the Park test, the Gamma distribution with log link was selected [26]. The logistic regression model was used to determine binary outcomes. All statistical analyses were conducted using SAS v.9.3 and STATA v.11 software.

\section{Results}

For the 1,920 RA patients identified, SIFRA scores ranged between 0 and 69.40, with a mean value of 14.21, and a standard deviation (STD) of 10.26. Mean SIFRA scores, (Table 2) were 7.05 (49.57\%), which composed of clinical and functional status variables, followed by 6.32 (44.47\%) for medications, $0.48(3.40 \%)$ of radiology and laboratory findings, 0.32 (2.25\%) for extra-articular manifestations (pulmonary nodules, subcutaneous nodules, vasculitis ever, and Felty's syndrome ever), and 0.04 $(0.31 \%)$ for surgical history (cervical spine fusion, hand/ foot joint replacement, foot joint/ankle/wrist fusion and total hip/knee/elbow/shoulder replacement).

Figure 2 shows the distribution of patients with the highest tercile of SIFRA scores across cities. The top four cities with the highest density of severe RA patients were Bolu (84\%), Kocaeli (63\%), Antalya (59\%) and Izmir (52\%).

Total costs, as well as components of total health care costs (copays, inpatient, outpatient, pharmacy costs) by SIFRA score tercile are presented in Figure 3. Histograms indicate that patients in the upper tercile of SIFRA incurred $€ 1,851$ higher health care costs, €1,647 higher pharmacy costs, €116 higher outpatient costs, and $€ 85$ higher inpatient costs. The difference in copayments was approximately $€ 3$.

Figure 4 presents the relationship between baseline SIFRA scores and the use of biologic therapies in the 


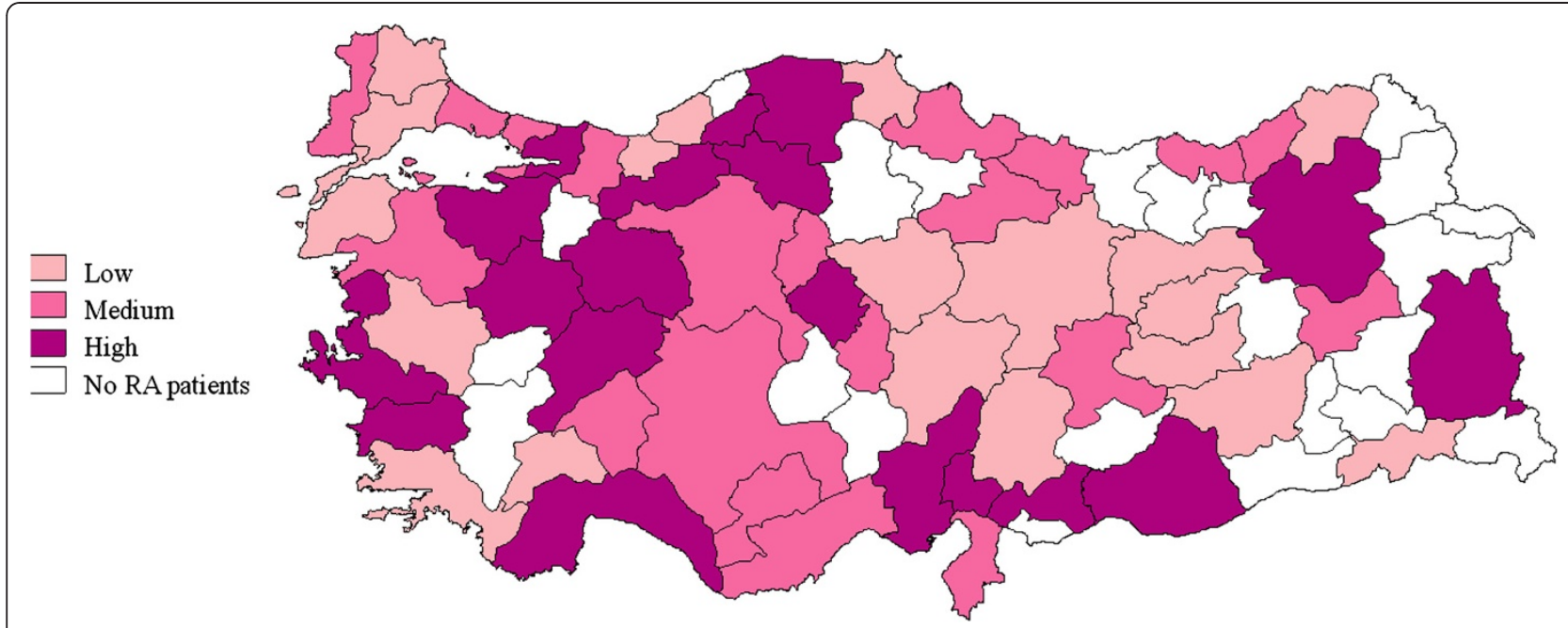

Figure 2 Rheumatoid arthritis severity distribution (by SIFRA terciles) across cities in Turkey.

follow-up period. The study results confirm the expectation of biologic use in more severe patients. Roughly one quarter $(25.75 \%)$ of the patients in the upper tercile of SIFRA were prescribed biologics, whereas only 5.6\% of patients in the lowest SIFRA tercile were prescribed biologics in the follow-up period. $(\mathrm{p}<0.001)$

Using multivariate analysis, the effect of SIFRA scores on health care costs, hospitalization and biologics use was estimated. After controlling for age, gender, region, and comorbidities, patients in the high SIFRA tercile were 5.16 times more likely to be prescribed biologics $(\mathrm{p}<0.001, \mathrm{CI}: 3.46-7.69)$ and incurred annual health care costs that were $€ 2,091$ greater $(p<0.001, C I$ : $€ 1,557$ $€ 2,625)$ than for those in the lower SIFRA tercile.

\section{Discussion}

Randomized clinical trials (RCT), although described as the "gold standard" to estimate treatment effects, have limitations. Small sample size, generalizability, trial costs and time restrictions limit the applicability of RCTs [27]. Observational studies can support clinical trials by providing real-world practice patterns across geographic regions, hospitals, and patient subgroups. However, the main limitation of observational studies is the lack of control for hidden bias. Hidden bias occurs when at least one variable belonging to the estimation model is missing from the data and, therefore, is not controlled for. When disease severity is missing from the data, the term is left in the error terms in risk-adjustment models, causing bias in the estimates. Although there are advanced techniques to statistically handle hidden bias, complex models often require additional variables that are rarely available in datasets $[28,29]$.

Due to the advancement in therapeutic options for RA patients and the high cost required to utilize them, the need for cost effective treatment methods is significant, particularly in the expanding aging population. RA expenditures are estimated at $€ 9,946$ in Belgium [18], $€ 5,029$ in the Netherlands [17], €4,000 in France, and $€ 2,312$ in Germany [16]. Overall, the estimated cost in Europe was calculated at $€ 2,835$, excluding pharmacy expenditures. Previous studies that attempted to estimate the costs of RA in Turkey were based on expert reports, local estimates and questionnaires. A recent study by Malhan et al. [15] estimated total annual medical costs per RA patient at $€ 2,917$. An earlier study, using data collected from hospital bills, estimated the annual cost to be $€ 2,669$. Other RA studies mostly pertained to disease prevalence and epidemiology in Turkey.

Table 2 SIFRA score distribution

\begin{tabular}{|c|c|c|c|c|c|c|}
\hline Variable & $\mathbf{N}$ & Mean & Min & Max & Median & STD \\
\hline SIFRA with Laboratory Data (SIFRA1) & 1,920 & $14.21(100 \%)$ & 0.00 & 69.40 & 12.10 & 10.26 \\
\hline Radiology \& Laboratory Findings & 1,920 & $0.48(3.40 \%)$ & 0.00 & 6.00 & 0.00 & 1.15 \\
\hline Clinical \& Functional Status & 1,920 & $7.05(49.57 \%)$ & 0.00 & 54.40 & 3.20 & 8.50 \\
\hline Extra-articular Manifestations & 1,920 & $0.32(2.25 \%)$ & 0.00 & 10.00 & 0.00 & 1.21 \\
\hline Surgical History & 1,920 & $0.04(0.31 \%)$ & 0.00 & 10.03 & 0.00 & 0.50 \\
\hline Medication & 1,920 & $6.32(44.47 \%)$ & 0.00 & 19.30 & 6.60 & 3.65 \\
\hline
\end{tabular}

SIFRA=severity index for rheumatoid arthritis; Min=minimum; Max=maximum; STD=standard deviation. 


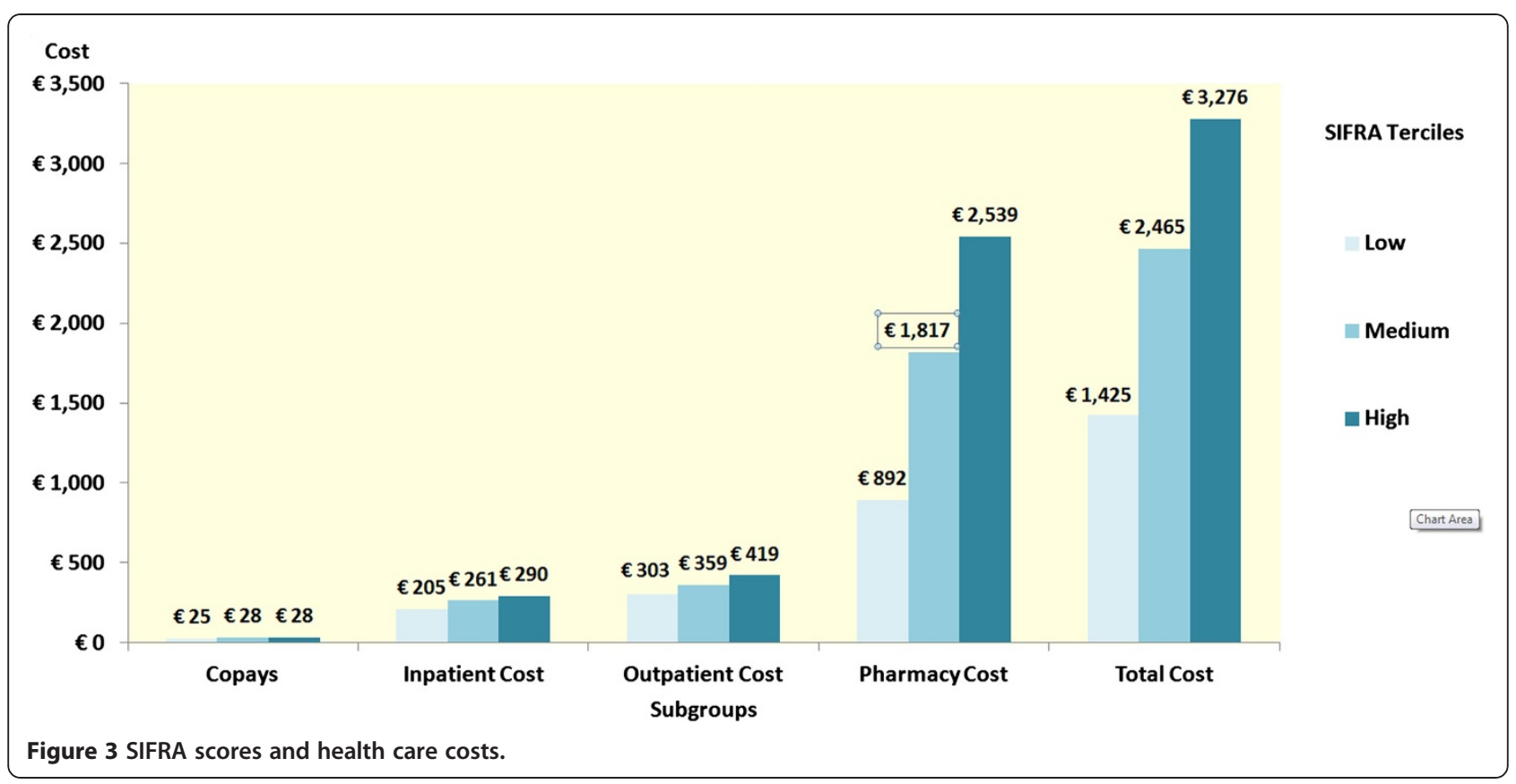

However, due to a lack of severity measures, the estimates from these prior studies were interpreted with caution. In some of the studies, severity was proxied with comorbidity index values, which were not specifically designed for RA. These indexes showed low correlation with the severity of RA.
A recent publication attempted to create a claims based, validated severity index for rheumatoid arthritis [23]. This index correlated highly with a record-based index score (RARBIS) and increased the prediction power of the models. This research applied the severity index on health care costs and utilization in patients with RA in Turkey,

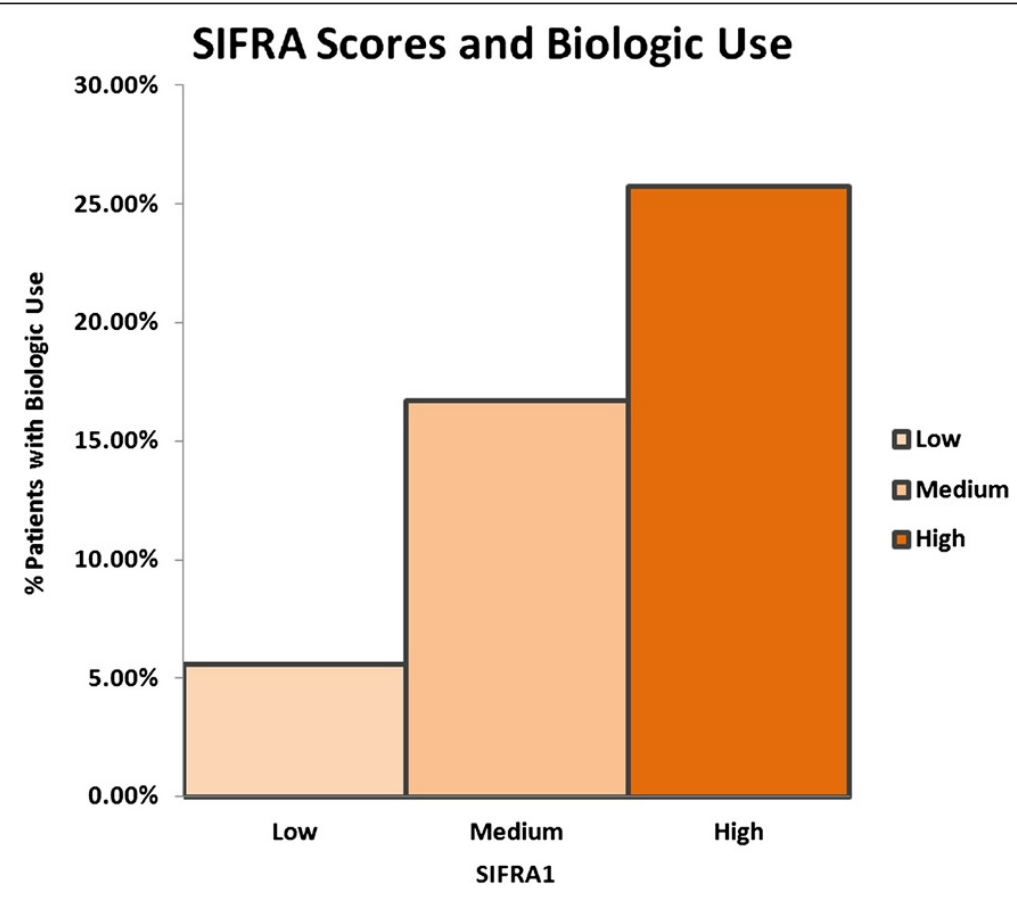

Figure 4 Association between SIFRA Scores and biologic use. 
using nationwide, real-world data to determine the association between RA severity and health care outcomes (such as cost, utilization and biologic use) in Turkey.

Note that one of the indicators in severity index for rheumatoid arthritis (SIFRA) are biological therapies. In order to estimate the effect of RA severity on biologic use, on needs to create this index using baseline use of biological therapies. All of the indicators should be calculated in the baseline to create the index otherwise one might have endogeneity problem in estimating the models. Thus, the estimators would be biased.

Although this study controlled for severity by using the claims-based severity index for RA, there are other limitations in this analysis, which are typical of any claimsbased data. Since claims data are collected for payment rather than research purposes, the presence of diagnostic codes on a medical claim does not necessarily prove existence of the actual disease. However, the probability that a patient with RA diagnostic codes also has RA was reported at 95\%. Two RA diagnoses occurring at least 60 days apart were applied in order to mitigate the incorrect coding and rule-out criteria. Diagnosis codes used to define comorbidities have over $90 \%$ specificity.

\section{Conclusion}

This paper applied the previously validated RA severity scores for diagnosed patients in Turkey. According to severity scores, the total medical costs of RA patients ranged from $€ 1,435$ to $€ 3,275$. The use of biologics was positively correlated with the severity score. Since statistically omitting a variable that belongs in population models provides biased and inconsistent estimates, any comparative effectiveness studies in RA treatment should include severity scores.

\section{Consent}

No patient identity or medical records were disclosed for the purposes of this study except in compliance with applicable law. Since the core study proposed herein does not involve the collection, use, or transmittal of individual identifiable data, patient approval/consent to conduct this study was not required.

\section{Competing interests}

The authors declare that they have no competing interests.

\section{Authors' contributions}

OB had full access to all of the data in the study and had taken responsibility for the integrity of the data and the accuracy of the analysis. Study concept and design were carried out by $O B$. Acquisition of data was made by $A B$. Analysis and interpretation of the data were carried out by OB. OB drafted the paper. $O B, A B, E B$, and $A A$ made critical revisions to the manuscript for important intellectual content. Statistical programming was conducted by EB. Administrative, technical, or material support was provided by OB. OB was responsible for the study supervision. All authors read and approved the final manuscript.

\section{Acknowledgements}

Editorial support was provided by Anne H. Dysinger and Elizabeth Moran of STATinMED Research.

\section{Author details}

'Internal Medicine Department, Rheumatology Division, The University of Michigan, 211 N 4th Avenue, Suite 2B, Ann Arbor, MI 48104, USA.

${ }^{2}$ STATinMED Research, 211 North 4th Avenue, Suite 2B, Ann Arbor, Ml 48104 , USA. ${ }^{3}$ STATinMED Research, Trump Towers, Büyükdere Caddesi, Şehit Ahmet Sokak, No: 1/405, $34010 S ̧ i s ̧ l i$, Istanbul, Turkey. ${ }^{4}$ Gastroenterology Clinic, Dıskapı Yıldırım Beyazıt Teaching and Research Hospital, Irfan Bastug CadDiskapi 06100, Ankara, Turkey. ${ }^{5}$ Program Development, Social Security Institution, Ziyabey Cad. No 6, 06520Balgat, Ankara, Turkey.

Received: 27 November 2012 Accepted: 21 February 2013

Published: 12 March 2013

\section{References}

1. Markenson JA: Worldwide trends in the socioeconomic impact and long-term prognosis of rheumatoid arthritis. Semin Arthritis Rheum 1991, 21(2 Suppl 1):4-12.

2. Lundkvist J, Kastäng F, Kobelt G: The burden of rheumatoid arthritis and access to treatment: health burden and costs. Eur J Health Econ 2008, 8(Suppl 2):S49-s60.

3. Alarcón GS: Epidemiology of rheumatoid arthritis. Rheum Dis Clin North Am 1995, 21(3):589-604.

4. Rasch EK, Hirsch R, Paulose-Ram R, Hochberg MC: Prevalence of rheumatoid arthritis in persons 60 years of age and older in the United States: effect of different methods of case classification. Arthritis Rheum 2003, 48(4):917-926.

5. Helmick CG, Felson DT, Lawrence RC, Gabriel S, Hirsch R, Kwoh CK, Liang MH, Kremers HM, Mayes MD, Merkel PA, Pillemer SR, Reveille JD, Stone JH, National Arthritis Data Workgroup: Estimates of the prevalence of arthritis and other rheumatic conditions in the United States: Part I. Arthritis Rheum 2008, 58(1):15-25.

6. Jönsson B, Kobelt G, Smolen J: The burden of rheumatoid arthritis and access to treatment: uptake of new therapies. Eur J Health Econ 2008, 8(Suppl 2):S61-s86.

7. Kremer JM, Lee JK: The safety and efficacy of the use of methotrexate in long term therapy for rheumatoid arthritis. Arthritis Rheum 1986, 29(7):822-831.

8. Kahlenberg JM, Fox DA: Advances in the medical treatment of rheumatoid arthritis. Hand Clin 2011, 27(1):11-20.

9. Scott D, Kingsley G: Tumor necrosis factor inhibitors for rheumatoid arthritis. N Engl J Med 2006, 355(7):704-712.

10. Yazici Y, Shi N, John A: Utilization of biologic agents in rheumatoid arthritis in the United States: analysis of prescribing patterns in 16,752 newly diagnosed patients and patients new to biologic therapy. Bull NYU Hosp Jt Dis 2008, 66(2):77-85.

11. Birnbaum H, Pike C, Kaufman R, Marynchenko M, Kidolezi Y, Cifaldi M: Societal cost of rheumatoid arthritis patients in the US. Curr Med Res Opin 2009, 26(1):77-90.

12. Clinical ACR: Guidelines Committee: Guidelines for the management of rheumatoid arthritis. American College of Rheumatology Ad Hoc Committee on Clinical Guidelines. Arthritis Rheum 1996, 39(5):713-722.

13. Lawrence RC, Helmick CG, Arnett FC, Deyo RA, Felson DT, Giannini EH, Heyse SP, Hirsch R, Hochberg MC, Hunder GG, Liang MH, Pillemer SR, Steen VD, Wolfe F: Estimates of the prevalence of arthritis and selected musculoskeletal disorders in the United States. Arthritis Rheum 1998, 41(5):778-799.

14. MacLean CH, Louie R, Leake B, McCaffrey DF, Paulus HE, Brook RH, Shekelle PG: Quality of care for patients with rheumatoid arthritis. JAMA 2000, 284(8):984-992.

15. Malhan S, Pay S, Ataman S, Dalkilic E, Dinc A, Erken E, Ertenli I, Ertugrul E, Gogus F, Hamuryudan V, Inanc M, Karaarslan Y, Karadag O, Karakoc Y, Keskin G, Kisacik B, Kiraz S, Oksel F, Oksuz E, Pirildar T, Sari I, Soy M, Senturk T, Taylan A: The cost of care of rheumatoid arthritis and ankylosing spondylitis patients in tertiary care rheumatology units in Turkey. Clin Exp Rheumatol 2012, 30(2):202-207.

16. Reginster JY: The prevalence and burden of arthritis. Rheumatology 2002, 41 (Suppl. 1):S3-S6.

17. Guillemin F, Durieux S, Daures JP, Lafuma A, Saraux A, Sibilia J, Bourgeois P, Sany J: Costs of rheumatoid arthritis in France: a multicenter study of 1109 patients managed by hospital-based rheumatologists. J Rheumatol 2004, 31(7):1297-1304. 
18. Verstappen S, Verkleij H, Bijlsma JW, Buskens E, Kruize AA, Heurkens AH, Van Der Veen MJ, Jacobs JW: Determinants of direct costs in Dutch rheumatoid arthritis patients. Ann Rheum Dis 2004, 63(7):817-824.

19. Westhovens $R$, Boonen $A$, Verbruggen $L$, et al: Healthcare consumption and direct costs of rheumatoid arthritis in Belgium. Clin Rheumatol 2005, 24(6):615-619.

20. Malhan S, Akbulut LA, Bodur H, Tulunay CF: Annual costs of rheumatoid arthritis in Turkey. Rheumatol Int 2010, 30(5):637-641.

21. Ting G, Schneeweiss S, Katz JN, Weinblatt ME, Cabral D, Scranton RE, Solomon DH: Performance of a rheumatoid arthritis records-based index of severity. J Rheumatol 2005, 32(9):1679-1687.

22. Cabral D, Katz JN, Weinblatt ME, Ting G, Avorn J, Solomon DH: Development and assessment of indicators of rheumatoid arthritis severity: results of a Delphi panel. Arthritis Rheum 2005, 53(1):61-66.

23. Baser O, Du J, Xie L, Wang H, Dysinger AH, Wang L: Derivation of severity index for rheumatoid arthritis and its association with health care outcomes. J Med Econ 2012, 15(5):918-924.

24. Elixhauser A, Steiner C, Harris D, Coffey R: Comorbidity measures for use with administrative data. Med Care 1998, 36(1):8-27.

25. Manning WG, Basu A, Mullahy J: Generalized modeling approaches to risk adjustment of skewed outcomes data. J Health Econ 2005, 24(3):465-488.

26. Manning WG, Mullahy J: Estimating log models: to transform or not to transform? J Health Econ 2001, 20(4):461-494.

27. Rossi PH, Freeman HE, Lipsey MW: Evaluation: A systematic approach. Sage Publications, Incorporated; 2003.

28. Wooldridge JM: Econometric analysis of cross section and panel data. Cambridge: Mass: MIT Press; 2002

29. Baser O: Too much ado about instrumental variable approach: is the cure worse than the disease? Value Health 2009, 12(8):1201-1209. doi:10.1111/ j.1524-4733.2009.00567.x. Epub 2009 May 29. http://www.ispor.org/ publications/value/editorial.asp Value in Health is published by ISPOR, Lawrenceville, NJ.

doi:10.1186/2191-1991-3-5

Cite this article as: Baser et al: Severity index for rheumatoid arthritis and its association with health care costs and biologic therapy use in Turkey. Health Economics Review 2013 3:5.

\section{Submit your manuscript to a SpringerOpen ${ }^{\circ}$ journal and benefit from:}

- Convenient online submission

- Rigorous peer review

- Immediate publication on acceptance

- Open access: articles freely available online

- High visibility within the field

- Retaining the copyright to your article 